\title{
Risk factors affecting post-pubertal high serum follicle-stimulating hormone in patients with hypospadias
}

\author{
Kimihiko Moriya ${ }^{1}$ (D - Michiko Nakamura ${ }^{1} \cdot$ Masafumi Kon ${ }^{1} \cdot$ Yoko Nishimura $^{1} \cdot$ Yukiko Kanno $^{1} \cdot$ Takeya Kitta $^{1}$. \\ Nobuo Shinohara ${ }^{1}$
}

Received: 17 August 2018 / Accepted: 15 February 2019 / Published online: 28 February 2019

(c) The Author(s) 2019

\begin{abstract}
Purpose The factors affecting spermatogenesis in adulthood in patients with hypospadias (HS) are not clearly understood. In the present study, risk factors affecting post-pubertal high serum follicle-stimulating hormone (FSH) were evaluated in patients with HS.

Materials and methods Among those with a history of HS surgery, patients in whom endocrinological evaluation regarding pituitary-gonadal axis was performed at 15 years of age or older between March 2004 and April 2018 were enrolled in the present study. High serum FSH was defined as greater than $10 \mathrm{mIU} / \mathrm{ml}$. The severity of HS was divided into mild and severe. Factors affecting the post-pubertal high serum FSH were estimated.

Results Seventy-nine patients were included in the present study. The severity of HS was mild in 35 and severe in 44 . History of undescended testis (UDT) was confirmed in 12. High serum FSH was detected in nine. On logistic regression model analysis, a history of UDT was the only significant factor for high serum FSH. The incidence of high serum FSH in patients with UDT was significantly higher than that in those without UDT $(58.3 \%$ vs $7.5 \%, p<0.01)$. When stratified by severity of HS and the presence of UDT, high serum FSH was detected in 70\% in patients with severe HS and UDT, whereas less than $10 \%$ in other groups.

Conclusions A history of UDT was a significant factor for post-pubertal high serum FSH in patients with HS. Accordingly, the presence of UDT may be a marker for impaired spermatogenesis in patients with HS, especially in severe cases.
\end{abstract}

Keywords Hypospadias $\cdot$ Undescended testis $\cdot$ Follicle-stimulating hormone $\cdot$ Spermatogenesis

\section{Introduction}

Hypospadias (HS) is one of the most common congenital anomalies in male children, occurring in $0.52-8.2$ of every 1000 live births $[1,2]$. Although there has been great surgical interest in short-term outcomes, such as fistula or stricture, information about the long-term outcomes of this anomaly is limited.

A multifactorial etiology, including genetic, endocrine, and environmental factors, is considered to be involved in the genesis of this anomaly [3]. As male urethral development is androgen-dependent, there may be a risk of gonadal

Kimihiko Moriya

k-moriya@med.hokudai.ac.jp

1 Department of Renal and Genitourinary Surgery, Hokkaido University Graduate School of Medicine, North-15, West-7, Kita-Ku, Sapporo 060-8638, Japan and reproductive disorders in patients with HS at puberty or later. Our previous study demonstrated endocrinological abnormalities in the pituitary-gonadal axis in patients with mild and severe HS [4]. In other previous reports, severe HS or associated genital abnormality, such as micropenis, undescended testis (UDT), or testicular tumor, were found to be risk factors for testicular and reproductive dysfunction [5-7]. In addition, birth weight (BW) or body mass index (BMI) has also been reported to affect the semen quality in the general population [8-13]. However, factors affecting spermatogenesis in patients with a history of HS in adulthood are not clearly understood.

In the present study, we investigated the risk factors affecting reproductive function in patients with HS. Given the difficulty in obtaining semen samples from asymptomatic patients, serum follicle-stimulating hormone (FSH) was used as a surrogate marker of spermatogenic function because previous studies demonstrated that FSH level in 
adults seems to be correlated with spermatogenetic activity $[14,15]$ and to be a predictive marker for the sperm retrieval rate in patients with non-obstructive azoospermia [16, 17], although exact role of FSH remains unclear.

\section{Patients and methods}

All patients with a history of HS surgery at our institute or affiliated hospitals were recommended to be followed for regular visits until the post-pubertal period. Medical charts of patients who visited our clinic for regular follow-up after HS surgery were retrospectively reviewed. Among them, patients who were born after July 1986 and in whom endocrinological evaluation regarding the pituitary-gonadal axis, including luteinizing hormone, FSH, and testosterone, was performed at 15 years of age or older between March 2004 and April 2018 were enrolled in the present study. If multiple endocrinological evaluations were carried out in one patient at 15 years of age or older, the final evaluation was used in the present study. Patients with obvious disorders of sex development or chromosomal abnormalities were excluded. High serum FSH was defined as greater than 10 $\mathrm{mIU} / \mathrm{ml}$. Severity of HS was divided into mild and severe based on the necessity of transecting urethral plate for correction of chordee deformity according to Koyanagi et al. [18]. Factors affecting post-pubertal high serum FSH were estimated.

JMP ${ }^{\circledR}$ pro version 13 was used for all statistical analyses. Statistical analysis was performed using Fisher's exact probability test or logistic regression model analysis for the determination of risk factors. $p<0.05$ was considered as significant.

The present study was approved by the Institutional Review Board of Hokkaido University Hospital (Approval number: 017-0066).

\section{Results}

\section{Patient characteristics (Table 1)}

Seventy-nine patients were included in the present study. Since endocrinological evaluation regarding the pituitary-gonadal axis was routinely performed at puberty or later, all patients with HS who visited during study period at 15 years of age or older were enrolled. The median BW, age at endocrinological evaluation, BMI, and Tanner pubic hair stage at evaluation were $2410 \mathrm{~g}$ (interquartile range 1626-3034), 17.5 years (range 15.0-27.0), $21.3 \mathrm{~kg} / \mathrm{m}^{2}$, and stage 5 (3-5), respectively. The severity of HS was mild in 35 and severe in 44. History of UDT was confirmed in 12 (unilateral in 5 and bilateral in 7/congenital in 3 and ascending
Table 1 Patient characteristics

\begin{tabular}{ll}
\hline Birth weight $(\mathrm{g}) \mathrm{IQR} /$ median $\pm \mathrm{SD}$ & $1626-3034$ \\
& $2410 \pm 877$ (unknown $4 \mathrm{pts})$ \\
Severity of HS & Mild: 35 pts Severe: $44 \mathrm{pts}$ \\
Undescended testis & $12 \mathrm{pts}$ \\
Unilateral & $5 \mathrm{pts}$ \\
Bilateral & $7 \mathrm{pts}$ \\
Congenital & $3 \mathrm{pts}$ \\
Ascending & $9 \mathrm{pts}$ \\
Age at evaluation (years) (median $\pm \mathrm{SD})$ & $15.0-27.0(17.5 \pm 2.1)$ \\
Tanner stage at evaluation & $\mathrm{III}: 2 \mathrm{pts}, \mathrm{IV}: 11 \mathrm{pts}, \mathrm{V}: 60$ \\
& $\mathrm{pts}(\mathrm{unknown}: 6 \mathrm{pts})$ \\
Body Mass Index at evaluation $\left(\mathrm{kg} / \mathrm{m}^{2}\right)$ & $12.2-32.6$ \\
$\quad($ median \pm SD) & $(21.3 \pm 3.7)$ \\
Serum FSH $(\mathrm{mIU} / \mathrm{ml})($ median $\pm \mathrm{SD})$ & $1.3-112.4(4.7 \pm 18.2)$ \\
$<10 \mathrm{mIU} / \mathrm{ml}$ & $67 \mathrm{pts}$ \\
$10-\mathrm{mIU} / \mathrm{ml}$ & $12 \mathrm{pts}$ \\
\hline
\end{tabular}

$I Q R$ Interquartile range

Table 2 Risk factors for high serum FSH

\begin{tabular}{lll}
\hline & $\begin{array}{l}\text { Odds ratio (95\% confi- } \\
\text { dence interval) }\end{array}$ & $p$ \\
\hline $\begin{array}{l}\text { Birth weight } \\
\text { Severity of HS }\end{array}$ & $0.612(0.0429-7.017)$ & n.s \\
$\quad$ Mild & Reference & \\
$\quad$ Severe & $2.743(0.744-13.180)$ & n.s \\
Undescended testis & Reference & \\
$\quad$ No & $17.36(4.196-82.242)$ & $<0.0001$ \\
$\quad$ Yes & $1.043(0.028-38.681)$ & n.s \\
Age at evaluation & & \\
Tanner stage at evaluation & Reference & \\
$\quad$ V & $5.250(0.7916-13.343)$ & n.s \\
$\quad$ V $>$ & $3.055(0.0560-166.738)$ & n.s \\
Body Mass Index at evaluation & &
\end{tabular}

in 9). The incidence of UDT was 2 of 35 (5.7\%) with mild HS and 10 of $44(22.7 \%)$ with severe HS $(p=0.06)$.

\section{Incidence and risk factors of high serum FSH}

High serum FSH was detected in 12 patients. On logistic regression model analysis, a history of UDT was the only significant factor for high serum FSH (Table 2). The incidence of high serum FSH in patients with UDT was significantly higher than that in those without UDT (58.3\% vs $7.5 \%, p=0.0002$ ) (Table 3 ). When compared between unilateral and bilateral UDT, or between congenital UDT and ascended testis, the incidence of high serum FSH was $3 / 5(60.0 \%)$ versus $4 / 7(57.1 \%)$, and $1 / 3(33.3 \%)$ versus $6 / 9$ 
Table 3 Impact of undescended testis on high serum FSH

\begin{tabular}{lll}
\hline Undescended testis & Incidence of high serum FSH & $p$ \\
\hline Yes & $7 / 12(58.3 \%)$ & 0.0002 \\
No & $5 / 62(7.5 \%)$ & \\
\hline
\end{tabular}

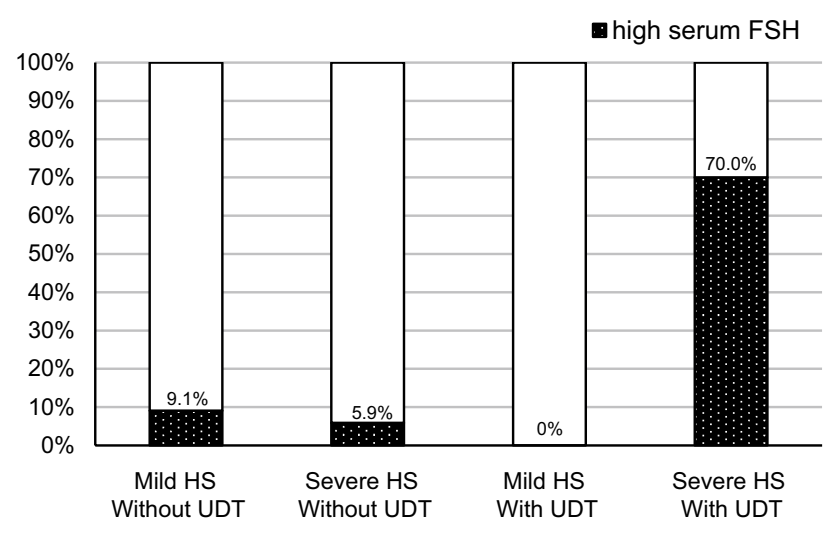

Fig. 1 Incidence of high serum FSH stratified by severity of HS and presence/absence of UDT. While the incidence of high serum FSH was as low as $10 \%$ in patients with mild HS without UDT $(n=33)$, in patients with severe HS without UDT $(n=34)$ or in patients with mild HS and UDT $(n=2), 70 \%$ showed high serum FSH in patients with severe HS and UDT $(n=10)$

(66.7\%), respectively. However, these differences were not statistically significant.

\section{Impact of severity of HS}

When patients were divided by severity of HS and the presence/absence of UDT, median value of serum FSH was 3.8 $\mathrm{mIU} / \mathrm{ml}$ in patients with mild HS without UDT $(n=33)$, 5.4 in patients with severe HS without UDT $(n=34), 2.4$ in patients with mild HS and UDT $(n=2)$, or 12.4 in patients with severe HS and UDT $(n=10)$, respectively. The rate of high serum FSH was $9.1 \%$ in patients with mild HS without UDT, 5.9\% in patients with severe HS without UDT, none in patients with mild HS and UDT, or 70\% in patients with severe HS and UDT, respectively (Fig. 1).

\section{Discussion}

The present study demonstrated that concomitant UDT was the only risk factor for high serum FSH in patients with HS in the post-pubertal period. The presence of UDT would be a marker for impaired spermatogenesis in patients with HS, especially in severe cases.

Previous reports on spermatogenesis in patients with HS in the post-pubertal period are limited. Asklund et al. [6]. found that the semen quality in men with HS and additional genital disorders (HAGD) was significantly poorer than that in those with isolated HS. The FSH level was also higher in men with HAGD than in those with isolated HS. Rey et al. [5]. reported that the risk of impaired Sertoli and Leydig cell function was higher in patients with HS and associated genital malformation than in those with isolated HS. Accordingly, as previously reported, some patients with HS, especially with additional genital disorders, are classified as having testicular dysgenesis syndrome [19]. These findings are consistent with the present study though patients' characteristics such as age at evaluation or severity of HS were different from previous studies.

Regarding the severity of HS, the present study demonstrated that it was not a significant factor affecting serum FSH. Kumar et al. [7]. recently reported poorer semen quality in patients with severe HS. However, much attention was not paid to associated genital anomalies such as UDT in their study. The current study and our previous report revealed that the incidence of high serum FSH was as low as $10 \%$, and was similar in isolated mild or severe HS [4]. And patients with severe HS tended to have UDT more frequently than those with mild HS in the present study. Accordingly, difference in the rate of concomitant UDT, not the severity of HS, was considered to affect the outcome of the study by Kumar et al. though the possibility that patients with both severe HS and UDT were at a higher risk of worse semen quality cannot be denied. Although gonadal dysfunction has been reported in both mild and severe HS [4, 20, 21], there are few reports on the differences in reproductive function based on the severity of HS. Thus, the impact of HS severity on reproductive function still remains unclear. Further studies are warranted.

In the current study, a history of UDT was the only significant risk factor for high serum FSH in patients with HS. As UDT itself carries the risk of impaired spermatogenesis, it is unknown whether concomitant HS increases the risk of impaired spermatogenesis. Previous studies demonstrated that the incidence of high serum FSH in patients with isolated bilateral UDT was significantly higher than that in patients with isolated unilateral UDT [22-24]. On the other hand, the incidence of high serum FSH in our study was similar in patients with HS and unilateral or bilateral UDT, although the number of patients was limited. As no difference was noted between patients with isolated unilateral UDT and the normal population regarding fertility [25], unilateral UDT in patients with HS may differ in pathology from isolated unilateral UDT in terms of spermatogenesis. Longer follow-up with lager number of patients are necessary to clarify this issue.

Nakamura et al. reported that a risk factor for testicular microlithiasis in patients with HS was concomitant UDT [26], which was also found to be a risk factor for high 
serum FSH in the current study. They found that the incidence of TM in patients with and without UDT was $43.8 \%$ and $9.5 \%$, respectively, which was similar with the incidence of high serum FSH in those with and without UDT (58.3\% or $7.5 \%$, respectively) in the present study. In addition, Asklund et al. reported that men with HS and testicular microlithiasis had a lower sperm concentration compared with men without microlithiasis [6]. As more than $40 \%$ of patients with HS and UDT did not have high serum FSH, testicular ultrasound may be beneficial to determine the risk of high serum FSH or impaired spermatogenesis in patients with HS and UDT. The prevalence of testicular microlithiasis in patients with UDT was reported to increase with time [27]; therefore, further studies are necessary to clarify the effects and optimal timing of testicular ultrasonography in patients with HS and UDT.

Low BW is a well-known risk factor for HS [28-30]. In previous reports, low BW was also found to be a risk factor for low semen quality in the general population, albeit controversial [8-11]. The current study demonstrated that BW was not associated with serum FSH. As the median BW for our patients was $2410 \mathrm{~g}$, indicating that more than half of the included patients had a low birth weight, it may be difficult to reach significance with this cohort. BMI was also reported to be a risk factor for poor semen quality, although there has been some debate [11-13]. However, BMI was not associated with serum FSH in our study. This may be due to the relatively low BMI at evaluation (median $21.3 \mathrm{~kg} / \mathrm{m}^{2}$ ) in our cohort.

There are several limitations in the present study. First, semen analysis was not performed because of the difficulty in obtaining semen samples form asymptomatic patients. Although previous studies demonstrated that FSH level in adults seems to be correlated with spermatogenetic activity and to be a predictive marker for the sperm retrieval rate in adults with non-obstructive azoospermia, FSH alone was reported to be insufficient for prediction [17]. In addition, median age of patients included in the current study was 17.5 , slightly younger to discuss the relation between serum FSH and semen quality based on previous reports. Second, there was no control in this study. Accordingly, although risk factors for high serum FSH among patients with HS were analyzed in the current study, it was not possible to demonstrate their impact of HS regarding spermatogenesis. A previous study reported that the semen quality of the majority of men with isolated HS was within the control range, but a slightly abnormal hormonal status was noted [6]. Thus, the outcome using semen analysis may differ from that of the current study. Last, the number of patients included in the present study was relatively low, especially for patients with UDT.

\section{Conclusion}

Our study demonstrated that concomitant UDT was the only risk factor for high serum FSH in the post-pubertal period in patients with HS. Accordingly, the presence of UDT may be a marker for impaired spermatogenesis in patients with a history of HS especially in severe cases. This information is useful for physicians when following up patients with HS after surgery.

Author contributions KM contributed to conception and design, data collection, data analysis, and manuscript writing/editing. MN was involved in conception and design, data analysis, and critical revision of the manuscript for scientific and factual content. MK and YN collected and analyzed the data. YK and TK critically revised the manuscript for scientific and factual content. NS supervised the study.

\section{Compliance with ethical standards}

Conflict of interest The author(s) declare that they have no competing interests.

Ethical standards This study has been approved by the institutional review board. The institutional review board-approved protocol number is 017-0066. The need for written informed consent was waived because this study was conducted by retrospective chart review.

Open Access This article is distributed under the terms of the Creative Commons Attribution 4.0 International License (http://creativeco mmons.org/licenses/by/4.0/), which permits unrestricted use, distribution, and reproduction in any medium, provided you give appropriate credit to the original author(s) and the source, provide a link to the Creative Commons license, and indicate if changes were made.

\section{References}

1. Levitt SB, Reda EF (1988) Hypospadias. Pediatr Ann 17 (1):48$49,53-44,57$

2. Springer A, van den Heijkant M, Baumann S (2016) Worldwide prevalence of hypospadias. J Pediatr Urol 12(3):152 e151-152 e157. https://doi.org/10.1016/j.jpurol.2015.12.002

3. Marrocco G, Grammatico P, Vallasciani S, Gulia C, Zangari A, Marrocco F, Bateni ZH, Porrello A, Piergentili R (2015) Environmental, parental and gestational factors that influence the occurrence of hypospadias in male patients. J Pediatr Urol 11(1):12-19. https://doi.org/10.1016/j.jpurol.2014.10.003

4. Moriya K, Mitsui T, Tanaka H, Nakamura M, Nonomura K (2010) Long-term outcome of pituitary-gonadal axis and gonadal growth in patients with hypospadias at puberty. $\mathrm{J}$ Urol 184(4 Suppl):1610-1614. https://doi.org/10.1016/j. juro.2010.04.022

5. Rey RA, Codner E, Iniguez G, Bedecarras P, Trigo R, Okuma C, Gottlieb S, Bergada I, Campo SM, Cassorla FG (2005) Low risk of impaired testicular Sertoli and Leydig cell functions in boys with isolated hypospadias. J Clin Endocrinol Metab 90(11):6035-6040. https://doi.org/10.1210/jc.2005-1306 
6. Asklund C, Jensen TK, Main KM, Sobotka T, Skakkebaek NE, Jorgensen N (2010) Semen quality, reproductive hormones and fertility of men operated for hypospadias. Int J Androl 33(1):80 87. https://doi.org/10.1111/j.1365-2605.2009.00957.x

7. Kumar S, Tomar V, Yadav SS, Priyadarshi S, Vyas N, Agarwal N (2016) Fertility potential in adult hypospadias. J Clin Diagn Res JCDR 10(8):Pc01-Pc05. https://doi.org/10.7860/ jcdr/2016/21307.8276

8. Sir-Petermann T, Hitchsfeld C, Codner E, Maliqueo M, Iniguez G, Echiburu B, Sanchez F, Crisosto N, Cassorla F (2007) Gonadal function in low birth weight infants: a pilot study. J Pediatr Endocrinol Metab JPEM 20(3):405-414

9. Faure C, Dupont C, Chavatte-Palmer P, Gautier B, Levy R (2015) Are semen parameters related to birth weight? Fertil Steril 103(1):6-10. https://doi.org/10.1016/j.fertnstert.2014.11.027

10. Whitcomb BW, Bloom MS, Kim S, Chen Z, Buck Louis GM (2017) Male birthweight, semen quality and birth outcomes. Hum Reprod (Oxf Engl) 32(3):505-513. https://doi.org/10.1093/humre $\mathrm{p} / \mathrm{dew} 345$

11. Ramlau-Hansen CH, Hansen M, Jensen CR, Olsen J, Bonde JP, Thulstrup AM (2010) Semen quality and reproductive hormones according to birthweight and body mass index in childhood and adult life: two decades of follow-up. Fertil Steril 94(2):610-618. https://doi.org/10.1016/j.fertnstert.2009.01.142

12. Sermondade N, Faure C, Fezeu L, Shayeb AG, Bonde JP, Jensen TK, Van Wely M, Cao J, Martini AC, Eskandar M, Chavarro JE, Koloszar S, Twigt JM, Ramlau-Hansen CH, Borges E Jr, Lotti F, Steegers-Theunissen RP, Zorn B, Polotsky AJ, La Vignera S, Eskenazi B, Tremellen K, Magnusdottir EV, Fejes I, Hercberg S, Levy R, Czernichow S (2013) BMI in relation to sperm count: an updated systematic review and collaborative meta-analysis. Hum Reprod Update 19(3):221-231. https://doi.org/10.1093/humupd/ dms050

13. Hart RJ, Doherty DA, McLachlan RI, Walls ML, Keelan JA, Dickinson JE, Skakkebaek NE, Norman RJ, Handelsman DJ (2015) Testicular function in a birth cohort of young men. Hum Reprod (Oxf Engl) 30(12):2713-2724. https://doi.org/10.1093/humrep/ $\operatorname{dev} 244$

14. Aksglaede L, Olesen IA, Carlsen E, Petersen JH, Juul A, Jorgensen N (2018) Serum concentration of anti-Mullerian hormone is not associated with semen quality. Andrology 6(2):286-292. https://doi.org/10.1111/andr.12456

15. Rohayem J, Luberto A, Nieschlag E, Zitzmann M, Kliesch S (2017) Delayed treatment of undescended testes may promote hypogonadism and infertility. Endocrine 55(3):914-924. https:// doi.org/10.1007/s12020-016-1178-0

16. Bromage SJ, Falconer DA, Lieberman BA, Sangar V, Payne SR (2007) Sperm retrieval rates in subgroups of primary azoospermic males. Eur Urol 51(2):534-539. https://doi.org/10.1016/j.eurur o.2006.08.032 (discussion 539-540)

17. Yang Q, Huang YP, Wang HX, Hu K, Wang YX, Huang YR, Chen B (2015) Follicle-stimulating hormone as a predictor for sperm retrieval rate in patients with nonobstructive azoospermia: a systematic review and meta-analysis. Asian J Androl 17(2):281-284. https://doi.org/10.4103/1008-682x.139259
18. Koyanagi T, Nonomura K, Yamashita T, Kanagawa K, Kakizaki $\mathrm{H}$ (1994) One-stage repair of hypospadias: is there no simple method universally applicable to all types of hypospadias? J Urol 152(4):1232-1237

19. Jorgensen N, Rajpert-De Meyts E, Main KM, Skakkebaek NE (2010) Testicular dysgenesis syndrome comprises some but not all cases of hypospadias and impaired spermatogenesis. Int J Androl 33(2):298-303. https://doi.org/10.1111/j.1365-2605.2009.01050 .x

20. Gearhart JP, Donohoue PA, Brown TR, Walsh PC, Berkovitz GD (1990) Endocrine evaluation of adults with mild hypospadias. J Urol 144(2 Pt 1):274-277

21. Eberle J, Uberreiter S, Radmayr C, Janetschek G, Marberger H, Bartsch G (1993) Posterior hypospadias: long-term followup after reconstructive surgery in the male direction. J Urol $150(5 \mathrm{Pt}$ 1):1474-1477

22. Lee PA, Coughlin MT (2001) Fertility after bilateral cryptorchidism. Evaluation by paternity, hormone, and semen data. Hormone research 55(1):28-32. https://doi.org/10.1159/000049960

23. Cortes D, Thorup J, Lindenberg S, Visfeldt J (2003) Infertility despite surgery for cryptorchidism in childhood can be classified by patients with normal or elevated follicle-stimulating hormone and identified at orchidopexy. BJU Int 91(7):670-674

24. Andersson AM, Jorgensen N, Frydelund-Larsen L, Rajpert-De Meyts E, Skakkebaek NE (2004) Impaired Leydig cell function in infertile men: a study of 357 idiopathic infertile men and 318 proven fertile controls. J Clin Endocrinol Metab 89(7):3161-3167. https://doi.org/10.1210/jc.2003-031786

25. Lee PA (1993) Fertility in cryptorchidism. Does treatment make a difference? Endocrinol Metab Clin N Am 22(3):479-490

26. Nakamura M, Moriya K, Nishimura Y, Nishida M, Kudo Y, Kanno Y, Kitta T, Kon M, Shinohara N (2018) Prevalence and risk factors of testicular microlithiasis in patients with hypospadias: a retrospective study. BMC Pediatr 18(1):179. https://doi. org/10.1186/s12887-018-1151-6

27. Nishimura Y, Moriya K, Nakamura M, Nishida M, Sato M, Kudo Y, Omotehara S, Iwai T, Wakabayashi Y, Kanno Y, Kitta T, Kon M, Shinohara N (2017) Prevalence and chronological changes of testicular microlithiasis in isolated congenital undescended testes operated on at less than 3 years of age. Urology 109:159-164. https://doi.org/10.1016/j.urology.2017.07.035

28. Akre O, Lipworth L, Cnattingius S, Sparen P, Ekbom A (1999) Risk factor patterns for cryptorchidism and hypospadias. Epidemiology (Cambridge, Mass) 10(4):364-369

29. Weidner IS, Moller H, Jensen TK, Skakkebaek NE (1999) Risk factors for cryptorchidism and hypospadias. J Urol 161(5):1606-1609

30. Jensen MS, Wilcox AJ, Olsen J, Bonde JP, Thulstrup AM, Ramlau-Hansen CH, Henriksen TB (2012) Cryptorchidism and hypospadias in a cohort of 934,538 Danish boys: the role of birth weight, gestational age, body dimensions, and fetal growth. Am J Epidemiol 175(9):917-925. https://doi.org/10.1093/aje/kwr421

Publisher's Note Springer Nature remains neutral with regard to jurisdictional claims in published maps and institutional affiliations. 